\title{
Gestão de Resíduos Sólidos em um Batalhão de Ensino, Instrução e Capacitação da Polícia Militar
}

Carlos Eduardo Souza de Araújo ${ }^{1}$ e Francisco Ricardo Duarte ${ }^{2}$

\begin{abstract}
Resumo: O presente artigo discorre sobre a gestão de resíduos sólidos no $3^{\circ}$ Batalhão de Ensino, Instrução e Capacitação de Juazeiro-Ba. O tema é abordado no contexto da gestão ambiental, e privilegia especialmente a importância de existir a gestão de resíduos sólidos em um ambiente de trabalho. Partindo de uma pesquisa de campo realizada dentro do ambiente do $3^{\circ}$ Batalhão, foi possível investigar se havia a gestão dos resíduos gerados e como se dava esse processo. Os resultados mostraram existir certa preocupação com o descarte de alguns dos resíduos sólidos gerados no refeitório, sendo uma parte destes resíduos separados dos demais e coletados diariamente por uma pessoa que utiliza como insumo. O óleo utilizado é separado em vasilhas e coletado por uma entidade para reaproveitamento. Devido ao fato do Batalhão estar em processo de reestruturação ainda não existe uma política de coleta seletiva implantada, sendo essa uma sugestão para o futuro.
\end{abstract}

Palavras-chave: Gestão de Resíduos; Gestão Ambiental; Coleta Seletiva.

\section{Management of Solid Waste in a Battalion of Teaching, Instruction and Training of the Military Police}

\begin{abstract}
This article discusses about the management of solid waste at the $3^{\text {rd }}$ Battalion of Teaching, Instruction and Training of Juazeiro-Bahia. The subject is addressed in the context of environmental management, and highlights the importance of the management of solid waste in a work place. Starting from a field research carried out within the $3^{\text {rd }}$ Battalion environment, it was possible to investigate whether there was management of the generated waste and how this process occurred. The results showed that there is some concern with the disposal of some of the solid residues generated in the refectory, being some of these residues separated from the others and collected daily by a person who uses as an input. The used oil is separated into pots and collected by an entity for reuse. Due to the fact that the Battalion is in the process of restructuring, there is still no selective collection policy in place, which is a suggestion for the future.
\end{abstract}

Keywords: Waste Management; Environmental Management; Selective collect.

\footnotetext{
${ }^{1}$ Universidade Federal do Vale do São Francisco - UNIVASF. Especializando em Gestão Pública.

Contato: eduardo_souza23@hotmail.com.br;

${ }^{2}$ Doutor em Difusão do Conhecimento (UFBA). Professor Adjunto III da Universidade Federal do Vale do São Francisco -

UNIVASF. Contato: fricardoduarte@ hotmail.com.br
} 


\section{Introdução}

Apesar das mudanças pelas quais vêm passando o nosso planeta ao longo dos anos, a gestão dos resíduos sólidos parece ser um dos problemas emergentes da sociedade moderna. À medida que o tempo passa, as quantidades de resíduos produzidas tornam-se cada vez maiores, tendo como consequência o aumento da poluição e dos descartes de resíduos em lugares inapropriados (RESÍDUOS SÓLIDOS: MANUAL DE BOAS PRÁTICAS NO PLANEJAMENTO, p.51). Portanto, um bom planejamento define as bases para a implantação e operação com alta qualidade da infraestrutura e dos sistemas de gestão de resíduos, que podem ser acessíveis em qualquer lugar onde os recursos locais estejam envolvidos.

Em 2 de Agosto de 2010, foi sancionada a Política Nacional de Resíduos Sólidos (PNRS) após duas décadas de debate no Congresso Brasileiro. Com esta decisão, o arcabouço legal brasileiro para Resíduos Sólidos se torna igual ao correspondente europeu. Desse modo, o Brasil estabeleceu sua Política Nacional de Resíduos Sólidos, definindo suas bases para planejar e implementar uma gestão apropriada dos resíduos sólidos (RESÍDUOS SÓLIDOS: MANUAL DE BOAS PRÁTICAS NO PLANEJAMENTO, p.48). Percebe-se que há a necessidade de incluir boas práticas de planejamento na Gestão de Resíduos Sólidos (GRS), para criar planos de gestão realísticos e factíveis, e de acordo com eles, resolver o problema dos resíduos, especialmente em países em desenvolvimento onde as condições financeiras nem sempre são favoráveis a implantação dessas práticas.

O conteúdo da Lei No 12.305/2010, leva em consideração seriamente todas as práticas no estado da arte relacionadas com a gestão dos resíduos sólidos, entre outras:

• Não geração;

- Redução dos resíduos gerados;

- Melhor utilização dos produtos - reuso sempre que possível;

- Separação das frações e processamento dos resíduos em usinas de reciclagem;

- Adoção de ações para recuperar a energia contida nos resíduos quando a reciclagem não for possível; e

- Tratamento e disposição de resíduos com a melhor tecnologia disponível, com custo acessível à população a ser atendida. 
Assim, além do que fora supramencionado, a política brasileira para os Resíduos Sólidos identifica o desenvolvimento dos Planos de Gestão dos Resíduos Sólidos, em todos os níveis, incluindo o nacional e estadual como a principal preocupação. Dessa forma, a principal razão para esta ação é que os planos de gestão dos resíduos sólidos integram os elementos citados anteriormente, oferecendo um plano bem construído para a implementação, exame de todas as soluções disponíveis e escolha da mais preferível, tanto em termos de aceitação social quanto de viabilidade econômica (RESÍDUOS SÓLIDOS: MANUAL DE BOAS PRÁTICAS NO PLANEJAMENTO, p.48).

Portanto, conforme tratado no Manual de Boas Práticas no planejamento sobre resíduos sólidos é o governo federal assim como os governos estaduais que têm que oferecer uma política clara de incentivos e estímulos para os municípios, que por sua vez devem buscar soluções conjuntas e regionalizadas, através de consórcios públicos. Porém, as pessoas, enquanto cidadãos, não podem se eximir da responsabilidade que têm em relação a gestão de resíduos sólidas gerados por ele, devendo seguir as boas recomendações para descarte desses resíduos.

Desse modo, o estudo em questão teve como objetivo analisar por meio de uma pesquisa de campo, realizada dentro do ambiente do $3^{\circ}$ Batalhão de Ensino, Instrução e Capacitação de Juazeiro-Ba ( $\left.3^{\circ} \mathrm{BEIC-BA}\right)$, como é realizada a gestão dos resíduos sólidos gerados no refeitório e em partes externas a esse ambiente, e de que forma se dava esse processo. Com o intuito, de buscar entender toda a dinâmica envolvida nas etapas de descarte dos resíduos sólidos gerados nesse local e seus reflexos para o meio ambiente.

\section{Revisão da Literatura}

\section{Histórico: $3^{\circ}$ Batalhão de ensino, instrução e capacitação de Juazeiro - Bahia}

Criado em 11 de agosto de 1896, no período histórico da Campanha de Canudos, o $3^{\circ}$ Batalhão já foi conhecido por outros nomes e nem sempre esteve sediado em Juazeiro. Fundado com o nome de $5^{\circ}$ Corpo de Regimento Policial da Bahia em 1896, passou a ser chamado de Batalhão de infantaria da brigada policial da Bahia, mais tarde Batalhão de Caçadores e também $3^{\circ}$ Corpo de Regimento Policial da Bahia, até que em 1967 recebeu aquele que vinha a ser o 
seu nome mais tradicional, $3^{\circ}$ Batalhão de Polícia Militar e em 2009 torna-se por fim, $3^{\circ}$ BEIC (ASCOM $3^{\circ}$ BEIC, 2017).

A unidade foi inicialmente instalada no Quartel dos Aflitos em Salvador e veio para a região do sertão para ajudar no combate ao cangaço em 1935 ficando inicialmente em Senhor do Bonfim vindo para Juazeiro em 22 de maio de 1951, funcionando na Rua Juvêncio Alves onde hoje fica a Receita Federal, na Praça da Bandeira, em 1962 mudou-se para a sede da Viação Baiana do São Francisco, antiga Franave na Orla II da cidade, até que em 18 de abril de 1978, instalou-se em definitivo no bairro Castelo Branco (ASCOM $3^{\circ}$ BEIC, 2017).

O Batalhão foi na maior parte de sua história uma Organização Militar eminentemente operacional voltado à atividade fim da instituição e chegou a ter quase mil homens em seu efetivo, sendo responsável por mais de 23 municípios, ocupando uma área de responsabilidade territorial de $72.029 \mathrm{~km} 2$ permitindo a segurança a uma população de mais de $600 \mathrm{mil}$ habitantes, mas, desde sempre o recrutamento e a formação de praças esteve entre suas atribuições, hoje é essa a sua exclusiva missão, suas companhias outrora orgânicas emanciparam-se em unidades independentes responsáveis agora pelo policiamento ostensivo da cidade (ASCOM $3^{\circ}$ BEIC, 2017).

O Batalhão Sertanejo, como é carinhosamente conhecido, tem como seu patrono o Coronel Terêncio dos Santos Dourado, ex-comandante geral da PMBA entre 1922 e 1928 e um dos responsáveis pela instalação da corporação na região norte do estado. $O$ primeiro comandante do batalhão foi o Major do Exército Salvador Pires de Carvalho Aragão e hoje é comandado pelo Tenente Coronel PM Jorge Sampaio Silva (ASCOM $3^{\circ}$ BEIC, 2017).

\section{A gestão ambiental}

Uma gestão adequada dos materiais descartados traz reflexos diretos na melhoria da saúde pública e na expectativa de vida (SEBRAE 2012, p.17). Sem dúvida, onde existir uma boa gestão dos materiais descartados baseada nos procedimentos recomendados pelo que preceituam as normas e leis vigentes, a saúde pública desse local só terá a ganhar em qualidade de vida. 
Não há um conceito unânime de gestão ambiental, todavia, há propostas para as empresas, sobre esse conceito, feitas pelos ambientalistas e organizações internacionais, sendo entendido como modelo de gestão ambiental o conjunto de decisões exercidas sob princípios de qualidade ambiental e ecológica preestabelecidos, com a finalidade de atingir e preservar um equilíbrio dinâmico entre objetivos, meios e atividades no âmbito da organização (ANDRADE; TACHIZAWA; CARVALHO, 2002).

Enquanto os sistemas de gestão da qualidade tratam das necessidades dos clientes, os sistemas de gestão ambiental atendem às necessidades de um vasto conjunto de partes interessadas e às crescentes necessidades da sociedade sobre proteção ambiental (ANDRADE; TACHIZAWA; CARVALHO, 2002).

Assim, cada forma de gestão está de acordo com o planejamento da instituição, ou seja, cada entidade possui estratégias diferentes conforme os objetivos traçados por sua direção. A gestão ambiental está voltada à compreensão do meio ambiente e ao crescimento da organização através de políticas de preservação ambiental, utilizando o meio ambiente de forma sustentável. Portanto, é necessário antes de qualquer coisa conhecer as normas ambientais para se fazer uma boa gestão de resíduos no local onde se pretende implantá-la.

\section{Normas Ambientais}

Podemos destacar entre as leis existentes, a Constituição da República Federativa do Brasil de 1988, a qual trata de forma ampla e integrada, a questão ambiental. Ela traz em seu artigo 225, que: "Todos têm direito ao meio ambiente, bem de uso comum do povo e essencial à sadia qualidade de vida, impondo-se ao Poder Público e à coletividade o dever de defendê-lo e preservá-lo para as presentes e futuras gerações" (BRASIL, 1988, p.36). Podemos encontrar na Constituição Federativa do Brasil, além do artigo supramencionado, outros que também foram criados visando proteger o meio ambiente, como exemplo, temos os artigos: $5^{\circ}, 23^{\circ}, 24^{\circ}$, $170^{\circ}$, dentre outros.

Sabe-se que existem várias Leis, Decretos e Medidas Provisórias tratando sobre o meio ambiente. Há também as normas não obrigatórias para todas as organizações conhecidas como ISO (International Organization for Standardization). Existe uma vasta gama de normas ISO. 
No entanto, para a certificação da gestão ambiental, destaca-se a ISO 14001. Todavia, existe, também, a ISO 9001 que certifica sistemas de qualidade para todo o tipo de empresas. Pode-se observar que, apesar de uma norma tratar sobre Qualidade (ISO 9001) e a outra sobre a Gestão Ambiental (ISO 14001), ambas possuem uma série de semelhanças, como: o comprometimento da organização, especificações, responsabilidades, registros, documentação, observância aos regulamentos, auditoria, análise crítica, entre outros.

Além dessas normas, também existem os guias que certificam a segurança e a saúde do trabalho (OHSAS 18001 e BS 8800), a responsabilidade social (SA 8000) e a Account Ability (AA1000). A ISO 9001 atende requisitos de clientes; a ISO 14.001, atende os interesses da comunidade na perspectiva dos impactos ambientais; a OHSAS 18.001 e BS 8800, atendem os interesses dos trabalhadores, já a SA 8000, atende os interesses dos públicos interno e externo da organização. Esse conjunto de normas e guias possuem requisitos que visam atender totalmente as necessidades da sociedade.

É importante salientar que a Lei Nacional de Resíduos Sólidos define três áreas básicas a serem abordadas (RESÍDUOS SÓLIDOS: MANUAL DE BOAS PRÁTICAS NO PLANEJAMENTO, p.51):

$>$ A preparação de planos de resíduos sólidos;

$>$ O princípio de responsabilidade compartilhada pelo ciclo de vida dos produtos entre governo, empresas e o público;

$>$ A participação dos catadores de recicláveis e de materiais reutilizáveis no sistema de logística reversa.

\section{A Política Nacional e o Plano Nacional de Resíduos Sólidos}

Segundo o SEBRAE (2012, p.21) a Política Nacional de Resíduos Sólidos (PNRS) foi instituída no Brasil pela Lei Federal 12.305, de agosto de 2010, e aborda desde os princípios que norteiam a questão até as diretrizes da gestão integrada e do gerenciamento de resíduos sólidos, incluídos os perigosos. Trata também das responsabilidades dos geradores e do poder público, e dos instrumentos econômicos aplicáveis, em caso de infrações. A questão dos rejeitos radioativos não faz parte da PNRS. 
A PNRS foi regulamentada pelo Decreto 7.404, de 2010, que instituiu o Comitê Interministerial (CI), formado por um total de 12 ministérios sob coordenação do Ministério do Meio Ambiente, que é responsável pela elaboração do Plano Nacional de Resíduos Sólidos, cuja versão preliminar já passou por audiências e consulta pública.

Dessa forma, o Plano trabalha com um horizonte de 20 anos e deve ser revisto a cada quatro anos. O seu objetivo é traçar um diagnóstico da situação atual dos resíduos sólidos, fixar metas de redução, reutilização, reciclagem, aproveitamento energético e definir os meios a serem utilizados para o controle e a fiscalização. O Plano Nacional de Resíduos Sólidos tem vínculo com o de saneamento básico, ambos devem estar interligados para que aja êxito e eficácia em sua aplicação.

\section{Resíduos Sólidos}

Para Bidone e Povinelli (1999), resíduos sólidos são todos aqueles resíduos nos estados sólido e semisólido, que resultam da atividade da comunidade de origem, seja industrial, doméstica, hospitalar, comercial, de serviços, entre outros.

Assim, os resíduos sólidos podem ser classificados de várias formas. Sendo que as principais são quanto às fontes geradoras, composição química, periculosidade e solubilização, entre outras, de acordo com a NBR 10.004/2004:

\footnotetext{
Resíduos sólidos são resíduos nos estados sólido e semisólido, que resultam de atividades de origem industrial, doméstica, hospitalar, comercial, agrícola, de serviços e de varrição. Ficam incluídos nesta definição os lodos provenientes de sistemas de tratamento de água, aqueles gerados em equipamentos e instalações de controle de poluição, bem como determinados líquidos cujas particularidades tornem inviável o seu lançamento na rede pública de esgotos ou corpos de água, ou exijam para isso soluções técnicas e economicamente inviáveis em face à melhor tecnologia disponível (ABNT, 2004, p.7).
}

A Lei $n^{\circ} 12.305$ de 02 de agosto de 2010, que institui a Política Nacional de Resíduos Sólidos (BRASIL, 2010), define gerenciamento de resíduos como um conjunto de ações exercidas direta ou indiretamente nas etapas de coleta, transporte, transbordo, tratamento e destinação final ambientalmente adequada dos resíduos sólidos e dos rejeitos. Já a gestão 
integrada de resíduos é definida como busca de soluções para os resíduos sólidos, de forma a considerar as dimensões política, econômica, ambiental, cultural e social e sob a premissa do desenvolvimento sustentável.

A única forma de reduzir os impactos ambientais dos resíduos sólidos é concentrar esforços na diminuição da geração destes, tratá-los e em caso de recicláveis, poupar recursos naturais. De maneira que o gerenciamento de resíduos sólidos não seja apenas uma novidade que ainda precise ser implementada, seguindo o que preceitua a Lei $\mathrm{n}^{\circ} 12.305$ de 02 de agosto de 2010, que institui a Política Nacional de Resíduos Sólidos. Para Bidone (2001), as soluções para a administração de resíduos são incontestavelmente ligadas a duas estratégias fundamentais: a redução na fonte ou seu tratamento.

Portanto, os resíduos sólidos produzidos pelo homem, de todas as áreas produtivas, são classificados de acordo com as atividades que lhes deu origem, por suas características físicas, elementos constituintes de sua estrutura e correlação com o impacto destes à saúde humana e ao meio ambiente. Os resíduos sólidos descartados nas grandes cidades, também chamado de lixo urbano, são coletados pelas prefeituras nas vias públicas e transportados a variadas unidades de destino final, como vazadouros a céu aberto, aterros sanitários controlados, estações de compostagem e triagem para o processo de reciclagem, incineração, etc.

\section{Classificação dos resíduos sólidos}

Podem-se classificar os resíduos sólidos, quanto à sua composição química em orgânicos ou biodegradáveis, como os restos de alimentos, podas de árvores, cascas, excrementos, dentre outros. Bem como, em inorgânicos recicláveis como vidros, metais, plásticos, papéis e em não recicláveis ou inservíveis como papéis higiênicos ou mesmo absorventes usados. Quanto à periculosidade, a ABNT através da NBR 10.004/2004, classifica para os efeitos desta norma os resíduos sólidos da seguinte forma:

1) Resíduos Classe I - Perigosos;

2) Resíduos Classe II - Não perigosos;

2.1) Resíduos Classe II A - Não inertes; 
2.2) Resíduos Classe II B - Inertes (ABNT, 2004, p.9).

Assim, os resíduos são definidos pela NBR 10.004/2004, segundo sua origem e também classificados de acordo com o seu risco em relação ao homem e ao meio ambiente em resíduos urbanos e resíduos especiais. Os Resíduos Classe I, possuem algum tipo de periculosidade, como inflamabilidade, corrosividade, toxicidade e patogenicidade. Neste grupo estão os resíduos de serviços de saúde, requerendo manejo através de Plano de Gerenciamento de Resíduos de Serviços de Saúde e destinação final por coleta especial.

Os resíduos sólidos urbanos, conhecidos como lixo doméstico, podem ser classificados nas classes II (não perigosos) e II-A (não inertes). Eles são gerados em residências, estabelecimentos comerciais ou por outras fontes geradoras nas cidades, como o lixo doméstico e todo tipo de resíduos recicláveis. Em meio a estes resíduos encontram-se: papel, papelão, vidro, latas, plásticos, trapos, folhas, galhos e terra, restos de alimentos, madeira e todos os outros detritos apresentados à coleta nas portas das casas pelos habitantes das cidades ou lançados nas ruas. Outra fonte geradora de resíduos é a construção civil, esses resíduos integram o tipo Classe II-B ou não perigosos e inertes, pois não possuem constituintes que possam ser solubilizados em água potável.

\section{Metodologia}

\section{Tipo e Natureza da Pesquisa}

Gil (2002) aponta três grandes grupos de pesquisa: exploratórias, descritivas e explicativas. Esta pesquisa pode ser classificada como descritiva, pois descreve uma situação real, concreta por meio da observação sistemática. De acordo com Gil (2002, p.42) as pesquisas descritivas têm como objetivo primordial a descrição das características de determinada população ou fenômeno ou, então, o estabelecimento de relações entre variáveis. 


\section{Procedimentos Metodológicos}

Para elaboração do presente artigo, foi realizada, a priori, uma revisão bibliográfica, por meio de artigos científicos, livros, sítios e monografias sobre resíduos sólidos, em especial a Lei $n^{\circ} 12.305$ de 02 de agosto de 2010, que institui a Política Nacional de Resíduos Sólidos. Tudo isso, a fim de adquirir embasamento teórico para que o trabalho pudesse ser realizado. Todo esse material deu suporte técnico para que se montasse o presente estudo de caso caracterizado aqui. Assim, o trabalho se deteve a um local concreto, o $3^{\circ}$ Batalhão de Ensino, Instrução e Capacitação localizado na cidade de Juazeiro Bahia. Cabe salientar que o $3^{\circ}$ BEICBA, está passando por um processo de reestruturação de suas instalações, e um desses processos diz respeito à terceirização do refeitório que foi realizada há pouco tempo por meio de licitação pública. No entanto, a pesquisa fora realizada antes da terceirização, o que abre a possiblidade de se fazer um novo estudo para comparar o que mudou.

\section{Coleta dos dados}

O levantamento dos dados e informações foi obtida na pesquisa de campo por meio da observação crítica e registrada por meio de fotografias dos locais onde é feito o descarte e depósito de todos os resíduos sólidos gerados pelo $3^{\circ}$ BEIC-BA. Assim, munidos dessas informações foi realizado um comparativo à base do que preceitua a Lei ${ }^{\circ} 12.305$ de 02 de agosto de 2010, que trata sobre resíduos sólidos, foco principal dessa pesquisa.

\section{Resultados e Discussões}

Administrar corretamente através de ações integradas e planejadas o lixo ou resíduos produzidos pela atividade humana é o que a literatura denomina de gerenciamento ou gestão de resíduos sólidos, que consiste em manejar estes resíduos desde a produção até sua destinação final de forma controlada e responsável, adotando uma política adequada que coordene estas atividades. 
A partir da análise dos dados coletados no levantamento feito no $3^{\circ}$ BEIC-BA foi possível verificar como mostrado na figura1, que os resíduos sólidos orgânicos gerados pelo refeitório são depositados em um galão, sendo feito o seu recolhimento diariamente por uma pessoa que utiliza esses resíduos como insumo. O restante dos resíduos também é descartado em galões e são recolhidos em dias intercalados pela empresa coletora de lixo do município de Juazeiro-Ba. O lixo coletado pela empresa no $3^{\circ}$ BEIC-BA segue para o aterro sanitário municipal, que passou por uma reforma em 2013, para se adequar às normas e exigências da legislação do Conselho Nacional do Meio Ambiente (CONAMA).

Contudo, foi possível notar conforme mostrado na figura 1, que ainda existem resíduos orgânicos e inorgânicos dentro do mesmo recipiente, ou seja, ainda não existe um gerenciamento eficaz na separação dos resíduos gerados. O preocupante é que esses resíduos armazenados descobertos atraem insetos e animais por conta do mau cheiro, trazendo riscos à saúde das pessoas que trabalham neste local. Pela imagem da figura 1, os resíduos gerados são basicamente das classes II (não perigosos) e II-A (não inertes).

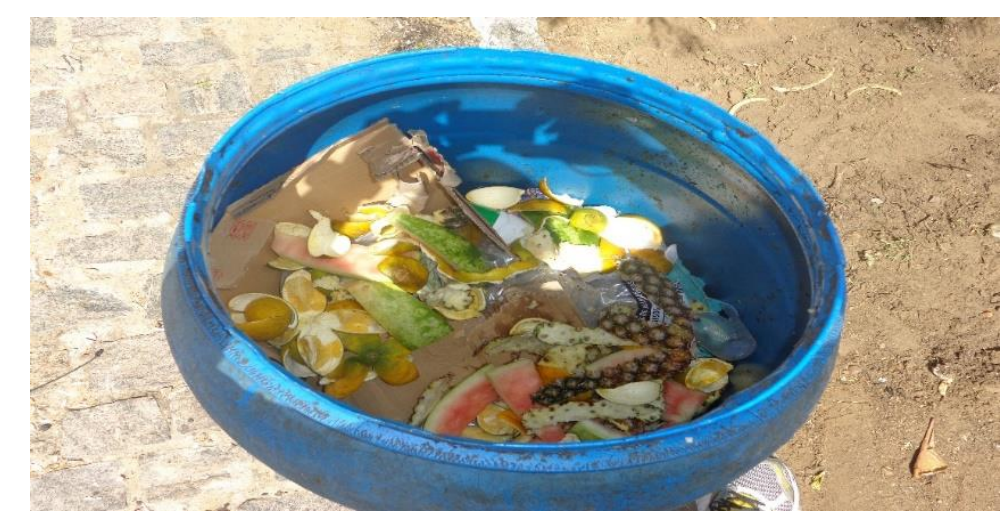

Figura 1: Lixeira do Refeitório do $3^{\circ}$ BEIC-BA.

Através da figura 2, foi possível perceber que na cozinha do refeitório os resíduos gerados estavam mal acondicionados, pois a lixeira se encontrava aberta o que acaba atraindo insetos, e consequentemente trazendo riscos à saúde das pessoas. Portanto, é necessário melhorar o acondicionamento desses resíduos, a começar por mantê-los com tampas para fechamento. 


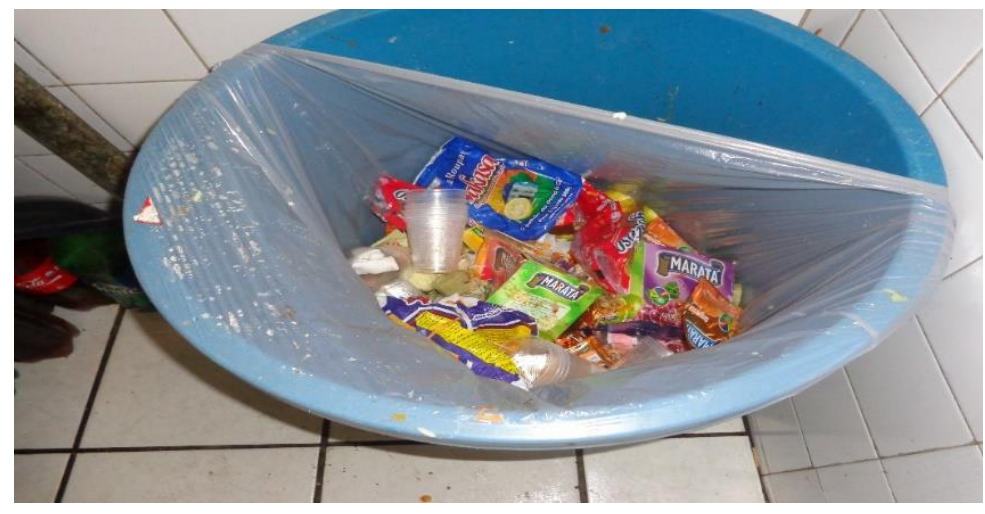

Figura 2: Lixeira da cozinha do refeitório do $3^{\circ}$ BEIC-BA.

Pode-se observar por meio da figura 3, que existem diversas lixeiras com sacos plásticos posicionadas em locais estratégicos, como nos corredores das sessões e setores do $3^{\circ}$ BEIC-BA. Sem dúvida, isso facilita o descarte dos resíduos e evita que o lixo seja dispensado em locais inadequados. Isso mostra que existe uma preocupação quanto à preservação da limpeza no local, confirmado pela boa disposição das lixeiras pelo ambiente. Tudo isso, facilita a implantação de um futuro projeto de coleta seletiva no local, que irá depender apenas de uma política de educação e conscientização por parte dos gestores e pessoas que trabalham nesse ambiente.

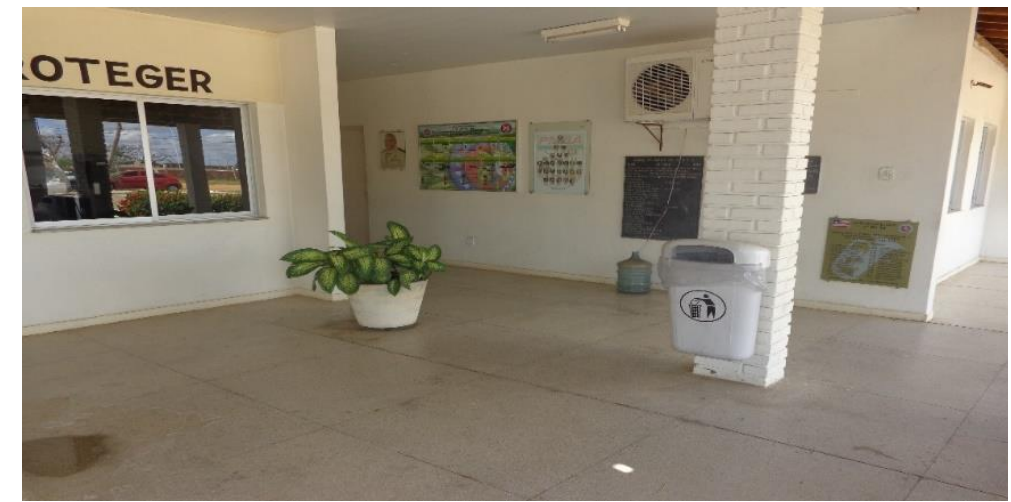

Figura 3: Disposição das lixeiras no $3^{\circ}$ BEIC-BA.

O fato da pesquisa se deter quase que exclusivamente ao refeitório da Unidade é devido à questão de ser esse o principal local gerador de resíduos do $3^{\circ} \mathrm{BEIC}-\mathrm{BA}$, temos nos demais 
setores resíduos das classes II (não perigosos) e II-A (não inertes), como papel, papelão, latas, plásticos, folhas, galhos e restos de alimentos.

A figura 4 , mostra a imagem da lixeira da cantina do $3^{\circ}$ BEIC-BA onde é vendido lanches, local onde é gerado resíduos das classes II e II-A. Pode-se perceber que apesar da lixeira obedecer ao padrão das normas quanto às cores para coleta seletiva, não existe uma gestão de educação e orientação para que isso seja seguido. Em todo ambiente do $3^{\circ}$ BEIC-BA, existe apenas essa lixeira de cor amarela para metal, faltando, uma verde para vidro, uma azul para papel e outra vermelha para plástico. Isso mostra que não há uma gestão para se fazer a coleta seletiva dentro dessa Unidade.

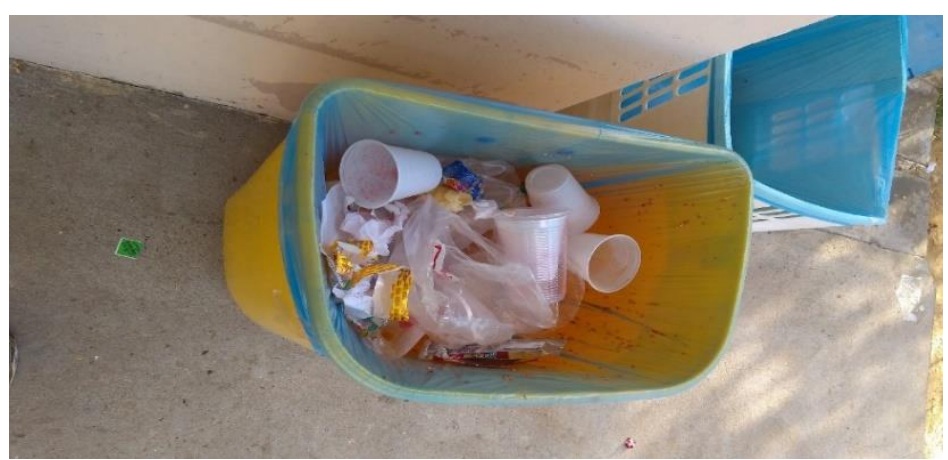

Figura 4: Lixeira da cantina do $3^{\circ}$ BEIC-BA.

Assim, a imagem da figura 4, permite observar que existem resíduos de diversos tipos e classificações dentro da lixeira onde só deveriam ser descartados materiais metálicos, devido a sua cor amarela. Portanto, apenas metais deveriam está dentro da lixeira amarela, mas tem-se também papel e plástico, resíduos que deveriam está em uma lixeira de cor azul e vermelha.

A situação retratada na figura 4 , se repete também na figura 5, onde tem-se resíduos metálicos, plásticos e papel. Isso mostra ser necessário haver uma gestão dos resíduos sólidos gerados dentro do $3^{\circ}$ BEIC-BA, por meio da implantação de um projeto de coleta seletiva e campanha educativa, como forma de contribuir para a preservação do meio ambiente. Uma campanha como essas seria fundamental para implantar uma boa gestão dos resíduos sólidos gerados no Batalhão. 


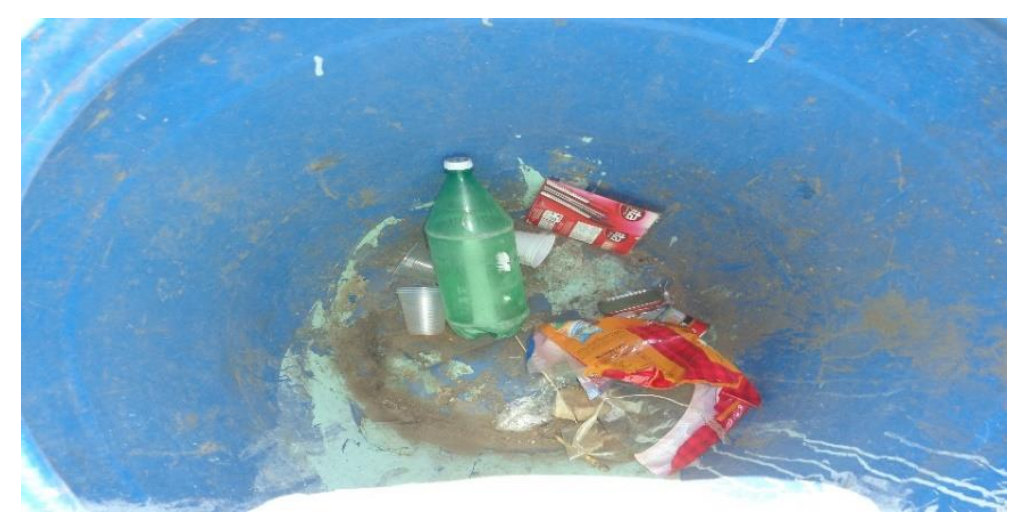

Figura 5: Lixeira do $3^{\circ}$ BEIC-BA.

Dessa forma, como o $3^{\circ}$ BEIC-BA, vem passando por um processo de reestruturação e melhoramento em suas instalações e estruturas, implantar uma cultura de boas práticas de gestão de resíduos sólidos dentro desse ambiente de trabalho não é algo que esteja fora da realidade e seria algo que viria a somar com as boas práticas de convivência e preservação no ambiente de trabalho. É importante que durante a fase de implantação da gestão de resíduos haja campanhas educativas sobre boas práticas com as pessoas que convivem e utilizam esse local de trabalho para que o projeto surta efeito.

\section{Considerações Finais}

Apesar de muito se falar em resíduos sólidos o seu gerenciamento ainda é pouco difundido nos mais diversos setores e ambientes e mesmo em locais onde há as lixeiras falta às vezes educação por parte das pessoas no momento em que é feito o descarte, sendo que existe a lixeira referente aquele resíduo gerado por aquela pessoa que está descartando. Com isso, percebe-se que existe uma necessidade crescente de soluções sustentáveis e coerentes para os problemas da gestão de resíduos sólidos produzidos em todo o mundo. Essa realidade não seria diferente no ambiente de estudo dessa pesquisa. Dessa forma, o presente artigo buscou analisar a gestão dos resíduos sólidos no $3^{\circ}$ BEIC-BA, onde se deu especial atenção aos resíduos gerados pelo refeitório, devido ser o local onde mais se produzem resíduos.

Foi observado que necessita haver uma atenção maior quanto ao procedimento de descarte dos resíduos gerados, pois alguns galões estavam descobertos e sem saco plástico 
atraindo insetos e animais. Verificou-se que havia em algumas lixeiras tanto resíduos orgânicos quanto inorgânicos misturados, demonstrando que ainda não existe uma preocupação por parte das pessoas quanto ao descarte desses resíduos ou mesmo o fato de ainda não existir a coleta seletiva possa de alguma forma influenciar na atitude dessas pessoas. Portanto, percebe-se que alguns locais onde os resíduos sólidos são descartados ou armazenados nem sempre são adequados, vindo a trazer riscos à saúde das pessoas. O que preocupa é a falta de consciência das pessoas no momento do descarte, sendo que eles próprios criam as condições que lhes sujeitam aos riscos de contaminação.

Assim, a partir da pesquisa realizada podem ser sugeridas algumas ações na busca por uma melhor gestão dos resíduos sólidos gerados no $3^{\circ}$ BEIC-BA:

- Fazer campanhas educativas dentro do $3^{\circ}$ BEIC-BA quanto à importância da gestão dos resíduos sólidos e da coleta seletiva;

- Aproveitar os galões que já existem e são utilizados como lixeira para fazer a separação do lixo em orgânico e inorgânico, ou mesmo fazer a separação por cores conforme rege a norma;

- Disponibilizar locais adequados para que os resíduos sejam descartados e armazenados até a coleta final pela empresa ou pessoa responsável pela coleta dos resíduos orgânicos;

- Motivar as pessoas que trabalham no Batalhão a participarem de campanha ou projeto de gestão de resíduos para que essa possa acontecer de maneira eficiente e eficaz.

Dessa forma, é preciso salientar que a gestão de resíduos sólidos no $3^{\circ}$ BEIC-BA, assim como em qualquer outro ambiente, depende de um planejamento estratégico voltado para as questões de geração e descarte dos resíduos sólidos baseados nas normas legais. Contudo, é importante ressaltar que o sucesso de tudo o que for planejado irá depender da conscientização de todos que trabalham no local, cabendo a estes serem gestores do seu próprio ambiente de trabalho que é um bem de todos. 


\section{Referências}

ANDRADE, Rui Otávio Bernardes de; TACHIZAWA, Takeshy; DE CARVALHO, Ana Barreiros. Gestão Ambiental: enfoque estratégico aplicado ao desenvolvimento sustentável. São Paulo: Pearson Education do Brasil, 2002.

ASCOM 30 BEIC, 2017. Disponível em: <http://www.cartazdacidade.com.br/noticias/9737,o-3-beicrealiza-as-comemora-es-de-seu-121-ano-de-funda-o.html>. Acesso em: 21 Maio 2018.

ASSOCIAÇÃO BRASILEIRA DE NORMAS TÉCNICAS. NBR 10.004/2004. Resíduos Sólidos Classificação. 2ed. Rio de Janeiro: Target Engenharia e Consultoria S/C ltda, 2004. 71p.

BIDONE, Francisco Ricardo Andrade (Coord). Resíduos sólidos provenientes de coletas especiais: Eliminação e Valorização. 1. ed. Porto Alegre: Rima/ABES, 2001, 240p.

BIDONE, Francisco Ricardo Andrade; POVINELLI, Jurandyr. Conceitos Básicos de Resíduos Sólidos. São Carlos: EESC - USP, 1999. 120p.

BRASIL. Lei $\mathrm{n}^{\circ}$ 12.305, de 02 de Agosto de 2010. Institui a Política Nacional de Resíduos Sólidos, altera a Lei $\mathrm{n}^{\circ} 9.605$ de 12/02/98 e dá outras providências. Diário Oficial da União. Brasília, DF, 03 Ago. 2010. n. 147.

BRASIL. Lei $\mathrm{n}^{\circ}$ 12.305, de 02 de Agosto de 2010. Institui a Política Nacional de Resíduos Sólidos, altera a Lei $n^{\circ} 9.605$ de 12/02/98 e dá outras providências. Diário Oficial da União. Brasília, DF, 03 Ago. 2010. n. 147.

BRASIL. Constituição da República Federativa do Brasil. Texto promulgado em 05 de Outubro de 1988. Senado Federal: Secretaria especial de editoração e publicações subsecretaria de edições técnicas. Brasília - 2010.

GIL, Antônio Carlos. Como elaborar projetos de pesquisa. 4 ed. São Paulo: Atlas, 2002.

RESÍDUOS SÓLIDOS: Manual de Boas Práticas no Planejamento. Disponível em: <http://www.abrelpe.org.br/manual_apresentacao.cfm>. Acesso em: 28 Abr. 2014.

SEBRAE. Gestão de Resíduos Sólidos. Disponível em: 〈http://www.reusa.com.br/biblioteca/Cartilha_Sebrae_Gestao_Residuos_Solidos_Abril_2012.pdf>. Acesso em: 15 Maio 2014.

\section{Como citar este artigo (Formato ABNT):}

ARAÚJO, Carlos Eduardo Souza de; DUARTE, Francisco Ricardo. Gestão de Resíduos Sólidos em um Batalhão de Ensino, Instrução e Capacitação da Polícia Militar. Id on Line Rev.Mult. Psic., 2018, vol.12, n.41, p.801-816. ISSN: 1981-1179.

Recebido: 11/06/2018

Aceito 19/07/2018 